ISSN: $2637-4676$

\title{
Diptera Interested Veteriner in Malaysia (Malay Version)
}

\author{
Uqbah Iqbal* \\ Department of Life Planner, Kuala Lumpur, Malaysia

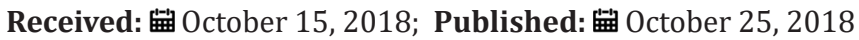 \\ *Corresponding author: Uqbah Iqbal, Department of Life Planner, Kuala Lumpur, Malaysia
}

\section{Opinion}

Written by Mohamad Fadzil Haji Yahya, this book is compiled from lecture notes given by the author to a veterinary medical student while attending a Veterinary Parasitology course. This note is part of a veterinary entomology note taught to students. This book does not contain a comprehensive description of all Diptera in Malaysia; Diptera described in this book is considered to be essential in terms of veterinary and is available in Malaysia. Most of the contents of this book are references from textbooks, magazines, papers, charts and so forth obtained by the author, and are mirrored by the study and observations carried out by the author themselves. Referrals made are listed in the reference list. It is hoped that this book will be useful for undergraduate and diploma students in the field of Veterinary Medicine or other students and researchers who are interested in the field of veterinary entomology. The absence of comprehensive information, especially in Bahasa Malaysia, with respect to this title has led authors to collect information into this booklet. The writing of this book aims to provide basic knowledge of veterinary flies, creams and mosquitoes in Malaysia.

The photographs and diagrams contained in this book are not intended for the purpose of making detailed diagnoses of one species but are simply a guide for practical identification to the genus level. Determination of species requires specialist services. Diptera is a group of people. Because these groups are not bony to support muscle and muscle attachment, their skin is thickened and hardened with chitin, a complex chemical, mostly from proteins. This hard and thick skin forms an outer frame. On the surface of the skin there are various scales, coarse fur and fine hair. An organ can be divided into three segments, namely head, thorax and abdomen. Each segment is considered to contain dorsal, ventral and lateral parts, each of which is called distorted, sternite and pleura. Diptera is a veterinarian in Malaysia including flies, tears and mosquitoes. These creatures are always disturbing livestock and cause stimulation due to their bites. The disorder may cause sensitization and miasis with secondary complications. These are also biological and mechanical vectors of animal disease pathogenic agents such as viruses, bacteria, protozoa, helmints and ricetsia, which cause disease and death to livestock, thus losing the financial resources for breeders. Diptera can be grouped into four subordons, namely Nematocera, Brachycera, Cyclorrhapha and Pupipara. Nematocera is composed of hwan which has a primitive shape. Cyclorrhapha contains a fairly specialized bead and Brachycera is an intermediary suborder that is located between these two groups. Pupipara should be included in the Cyclorrhapha suborder but due to certain features then pupils will be separated into separate suborders. Every activity involving veterinary needs requires the ability to collect and retrieve it. Many sampling techniques and collections can be used. The collection is important for identifying the genus or species involved as a vector in the transfer of a disease agent. By this way the escort can be arranged based on the biological knowledge of the species involved. The method chosen for this Diptera collection depends on species and objectives. Number of Diptera is determined by two important factors, abiotic factor and biosis factor. Abiotic factors are environmental factors such as temperature, breeding grounds and air humidity. Biosis factors are true enemies including parasites, predators and pathogens. The climate of a place is a major factor that generally determines the potential of breeding Diptera populations. However, the situation in the home can change this environment. The true enemies of Diptera play an important role that can set Diptera population naturally. Temperatures in an area affect Diptera's development velocity and the number of generations to be gained annually. 


\section{(C) \\ This work is licensed under Creative Commons Attribution 4.0 License}

To Submit Your Article Click Here:

Submit Article

DOI: 10.32474/CIACR.2018.05.000206

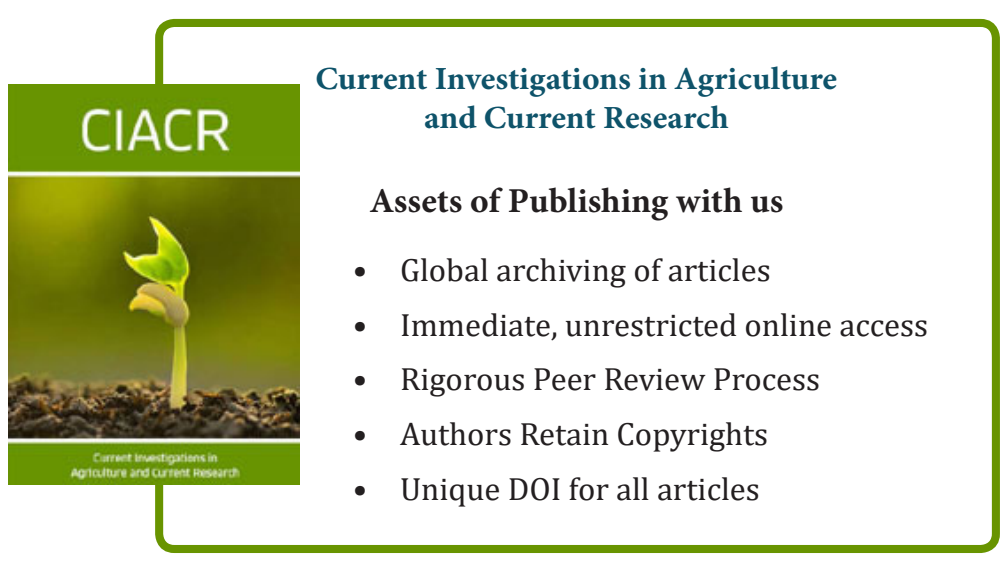

